\title{
PENINGKATAN KOMPETENSI GURU PAUD DALAM MENGEMBANGKAN MEDIA PEMBELAJARAN INOVATIF
}

\author{
Maya Masitha Astriani' ${ }^{1),}$ Mal Alfahnum ${ }^{2)}$ \\ Program Studi Pendidikan Matematika, Fakultas Matematika Ilmu Pengetahuan Alam, \\ Universitas Indraprasta PGRI
}

\begin{abstract}
Abstrak
Pendidikan anak usia dini merupakan salah satu jenjang pendidikan paling dasar untuk tumbuh kembang anak. Kualitas guru PAUD yang profesional akan menentukan perkembangan anak usia dini. Guru yang melaksanakan pendidikan pada anak usia dini disyaratkan memiliki tingkat pendidikan dan kompetensi khusus, namun pada kenyataan di lapangan banyaknya guru PAUD yang belum memenuhi standar kompetensi yang ditetapkan. Kegiatan pengabdian masyarakat ini bertujuan meningkatkan kompetensi guru Pendidikan Anak Usia Dini (PAUD) dalam mengembangkan media pembelajaran inovatif sehingga pembelajaran yang dilakukan dapat memberikan pengetahuan dan pengalaman yang bermakna bagi siswa. Metode yang digunakan adalah ceramah, praktek membuat media pembelajaran dan peer teaching dengan menggunakan media pembelajaran yang telah dikembangkan. Hasil yang diperoleh kompetensi guru bertambah, media pembelajaran pada lembaga PAUD bervariasi, dan kreativitas guru meningkat setelah mengikuti pelatihan.
\end{abstract}

Kata Kunci: kompetensi, guru PAUD, media pembelajaran

\begin{abstract}
Early childhood education is one of the most basic levels of education for child development. The quality of professional PAUD teachers will determine early childhood development. Teachers who carry out education in early childhood are required to have a level of education and special competencies, but in reality on the ground many PAUD teachers do not meet the competency standards set. This community service activity aims to improve the competence of Early Childhood Education (PAUD) teachers in developing innovative learning media so that learning can provide meaningful knowledge and experience for students. The method used is lectures, the practice of making learning media and peer teaching using learning media that have been developed. The results obtained increased teacher competence, learning media in PAUD institutions varied, and teacher creativity increased after attending the training.
\end{abstract}

Keywords: competency, PAUD teachers, learning media

Correspondence author: Maya Masitha Astriani, maya.masitha@gmail.com,Jakarta, Indonesia 


\section{PENDAHULUAN}

Pendidikan anak pada usia dini telah disadari memegang peranan yang sangat penting dikarenakan pada masa anak berusia $0-5$ tahun tersebut merupakan masa yang disebut sebagai masa keemasan. Pada masa tersebut anak berpotensi mempelajari banyak hal dengan sangat cepat, pertumbuhan dan perkembangannya terjadi secara pesat, baik fisik maupun mental (Suyanto, 2005). Dari hasil penelitian terhadap anakanak dari golongan ekonomi lemah yang diketahui kurang memperoleh rangsangan mental selama masa prasekolah ternyata pada pendidikan selama 10 tahun berikutnya tidak memberi hasil yang memuaskan (Adiningsih, 2001). Dengan demikian dapat disimpulkan bahwa pendidikan anak pada usia dini merupakan hal yang penting. Sejalan dengan hal tersebut, kini Kementerian Pendidikan dan Kebudayaan menggulirkan kebijakan strategis yaitu percepatan dan perluasan layanan Pendidikan Anak Usia Dini (PAUD).

Pendidikan bagi anak usia dini diselenggarakan melalui jalur formal dan non formal. Jenis pendidikan anak usia dini formal diantaranya adalah Taman Kanak Kanak (TK) dan Raudhatul Athfal (RA). Sementara itu jenis pendidikan anak usia dini non formal diantaranya adalah Taman Penitipan Anak (TPA), Kelompok Bermain/ Play Group (KB/PG), dan Pos PAUD. Akhir-akhir ini berbagai jenis pendidikan anak usia dini yang muncul di masyarakat semakin berkembang. Hal tersebut mengindikasikan bahwa semakin meningkatnya kesadaran masyarakat tentang pentingnya pendidikan yang sesuai dengan tahap perkembangan anak sejak usia dini. Hal tersebut juga merupakan keberhasilan kebijakan yang dicanangkan pemerintah (Prihatin, 2012).

Guru atau pendidik PAUD berperan penting dalam pengembangan karakter siswa atau anak didik yang nantinya merupakan generasi penerus bangsa (Hariyanti, 2012). Pemerintah melalui Permendiknas Nomor 16 tahun 2007 menetapkan kualifikasi akademik dan standar kompetensi bagi para pendidik, hal tersebut tentunya bertujuan untuk menjaga mutu pendidikan di Indonesia. Pada pendidikan PAUD, idealnya kualifikasi akademik yang dipersyaratkan adalah minimum diploma empat (D-IV) atau sarjana (S1) dalam bidang pendidikan anak usia dini atau psikologi yang diperoleh dari program studi terakreditasi. Sementara itu standar kompetensi yang dipersyaratkan mencakup kompetensi pedagogik, kompetensi kepribadian, kompetensi sosial, dan kompetensi profesional.

Apabila menelaah pada kriteria yang ditetapkan pemerintah, tentu tidak mudah menjadi seorang pendidik pada PAUD. Namun demikian, pada kenyataan di lapangan masih dijumpai banyaknya tenaga pendidik PAUD yang belum memenuhi kualifikasi tersebut. Sehingga para pendidik PAUD biasanya cenderung kurang memahami tahapan pertumbuhan dan perkembangan anak baik secara fisik dan psikis, kurang memiliki gagasan kreatif dalam menggunakan media pembelajaran dan permainan melakukan permainan dan serta kesulitan dalam merancang kegiatan belajar yang sesuai dengan tema. Hal tersebut senada dengan yang disampaikan oleh Nugroho (2014) bahwa pendidik PAUD yang berkompeten masih belum mencukupi. Munculnya kesadaran masyarakat untuk menyelenggarakan pendidikan bagi anak usia dini tidak diikuti dengan adanya pendidik anak usia dini yang benar-benar kompeten di bidangnya.

Untuk mencapai kompetensi seperti yang dipersyaratkan oleh Permendiknas No 16 tahun 2007 tentang Standar Kualifikasi Akademik dan Kompetensi Guru bukanlah sesuatu hal yang mudah bagi para pendidik PAUD. Adanya kendala finansial menyebabkan para pendidik PAUD tidak memungkinkan untuk melanjutkan pada 
jenjang studi yang lebih tinggi di Perguruan Tinggi. Sehingga kompetensi profesional dan pedagogik yang diharapkan dimiliki pendidik PAUD belum tentu dimiliki oleh mereka.

Dari hasil monitoring yang dilakukan tim abdimas diperoleh informasi bahwa pengetahuan dan keterampilan yang dimiliki para pendidik (kader) PAUD dalam melaksanakan kegiatan belajar dan mengajar cenderung masih kurang, khususnya dalam menggunakan dan mengembangkan media pembelajaran. Selain itu ketersediaan alat peraga edukatif masih sangat terbatas karena dalam pengadaannya masih mengandalkan bantuan dari pemerintah dan sumbangan dari pihak luar yang waktunya tidak menentu.

Berdasarkan analisis permasalahan, penting dilakukan pelatihan untuk meningkatkan kompetensi dan kreativitas guru PAUD khususnya dalam mengembangkan media pembelajaran agar siswa mengalami pembelajaran yang lebih bermakna.

\section{METODE PELAKSANAAN}

Metode yang digunakan menggunakan konsep pelatihan dimana peserta diberikan pembekalan materi dan pelatihan pengembangan media. Dari pembekalan materi diharapkan peserta dapat mengetahui pentingnya penggunaan media pembelajaran dalam proses belajar mengajar. Sedangkan untuk pelatihan pengembangan media diharapkan peserta dapat membuat media pembelajaran.

Adapun langkah kegiatan pengabdian masyarakat yang akan dilaksanakan sesuai dengan skema di bawah ini:

1. Tahap persiapan. Koordinasi internal antar tim abdimas untuk penentuan tema kegiatan, pembentukan tim, penyusunan proposal, penjadwalan, pendanaan dan persiapan pelaksanaan.

Langkah selanjutnya dilakukan survei lapangan yang bertujuan untuk mengamati situasi dan keadaan tempat yang direncanakan sebagai objek sasaran. Setelah itu dilakukan serangkaian tahapan sebagai berikut:

a. Koordinasi dengan mitra

Tim pelaksana program abdimas berkoordinasi dengan mitra dalam hal ini ketua yayasan Rumah Ceria Indonesia untuk menentukan kesepakatan mufakat mengenai konsep dan rencana pelaksanaan abdimas.

b. Penyusunan bahan pelatihan media

Bahan pelatihan yang disusun oleh tim pelaksana abdimas berupa modul. Modul berisi materi garis besar pengembangan media pembelajaran.

c. Publikasi Kegiatan

Sosialisasi kegiatan bertujuan untuk memberikan informasi tentang rencana serangkaian pelaksanaan kegiatan yang disampaikan kepada guru-guru PAUD di wilayah kelurahan Pengadegan.

2. Tahap pelaksanaan

a. Persiapan alat dan bahan

Sebelum pembuatan media pembelajaran dilakukan persiapan alat dan bahan. Alat yang digunakan meliputi perlengkapan laptop, layar dan infokus yang digunakan untuk memvisualisasikan bahan pelatihan serta kit perlengkapan yang akan digunakan oleh peserta untuk mengembangkan media pembelajaran.

b. Pelaksanaan kegiatan 
Mensosialisasikan konsep pentingnya penggunaan media pembelajaran kepada guru-guru PAUD di wilayah kelurahan Pengadegan. Selanjutnya pelatihan pembuatan media pembelajaran, berupa demonstrasi pelatihan pembuatan media pembelajaran, pendampingan pembuatan media pembelajaran agar mampu menghasilkan media pembelajaran inovatif dan menarik dan peer teaching menggunakan media pembelajaran yang telah dikembangkan.

\section{Evaluasi Kegiatan}

Mengevaluasi pelaksanaan program yang telah dilaksanakan. Evaluasi ini dilakukan oleh tim abdimas bersama mitra, untuk mengetahui hambatan dan masukan pelaksanaan pelatihan serta kelanjutan kerjasama.

\section{HASIL DAN PEMBAHASAN}

Kegiatan pengabdian masyarakat berupa pelatihan ini dilaksanakan pada Sabtu, 8 Desember 2019 pukul 09.00-12.00 WIB bertempat di Preschool dan Daycare Rumah Ceria dengan peserta pelatihan sebanyak 13 orang. Kegiatan dengan konsep pelatihan dimana peserta diberi pembekalan materi, workshop pembuatan media pembelajaran inovatif dari bahan daur ulang dan monitoring dapat berjalan dengan baik dan lancar. Pembekalan materi dilakukan dengan metode ceramah dan tanya jawab, workshop pembuatan media pembelajaran dilakukan dengan metode praktek dan monitoring dilakukan dengan pendampingan.

Pelaksanaan pelatihan terbagi menjadi tiga sesi, dengan perincian sebagai berikut:

1. Pelaksanaan sesi pertama dilakukan setelah pembukaan oleh MC, Tilawah dan sambutan-sambutan, pada pukul 09.30-10.30 WIB. Materi yang diberikan mengenai pentingnya penggunaan media dalam kegiatan pembelajaran PAUD oleh Dr. Khasanah, M.Pd dan Maya Masitha Astriani, M.Pd.

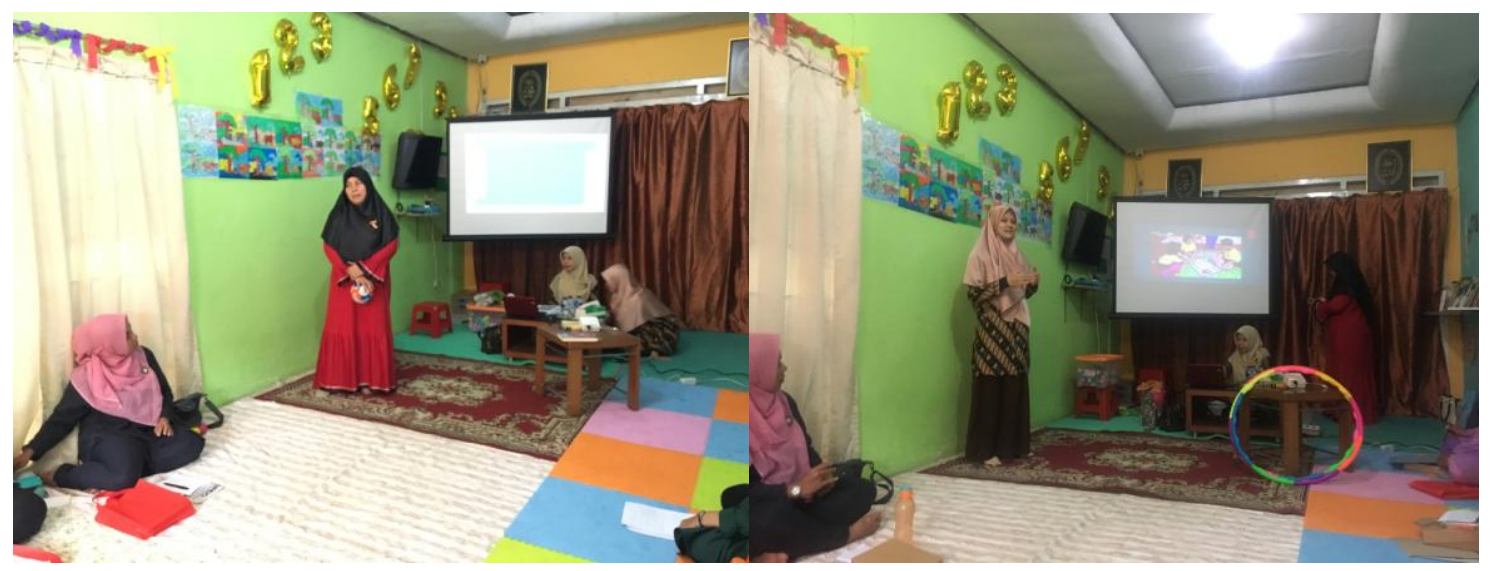

Gambar 1 Penyampaian materi oleh Dr. Khasanah, M.Pd (kiri) dan Maya Masitha Astriani, M.Pd (kanan)

2. Pelaksanaan sesi kedua pada pukul 10.30-11.30 WIB. Materi yang diberikan mengenai pembuatan media pembelajaran inovatif dari bahan daur ulang oleh Mal Alfahnum, M.Pd, sesuai handout dan bahan yang telah disiapkan tim abdimas. Pada sesi kedua ini, peserta diminta mengembangkan media sesuai arahan dari pemateri dan kreatifitas peserta. Peserta didampingi oleh tim abdimas untuk mengantisipasi hambatan dan kesulitan dalam pengembangan media. 


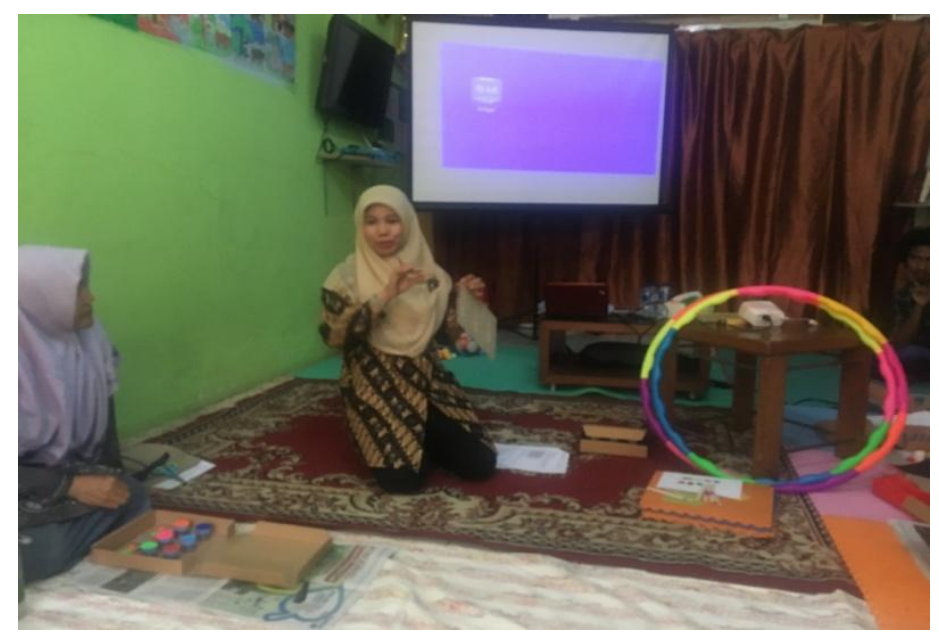

Gambar 2 Penyampaian materi oleh Mal Alfahnum, M.Pd

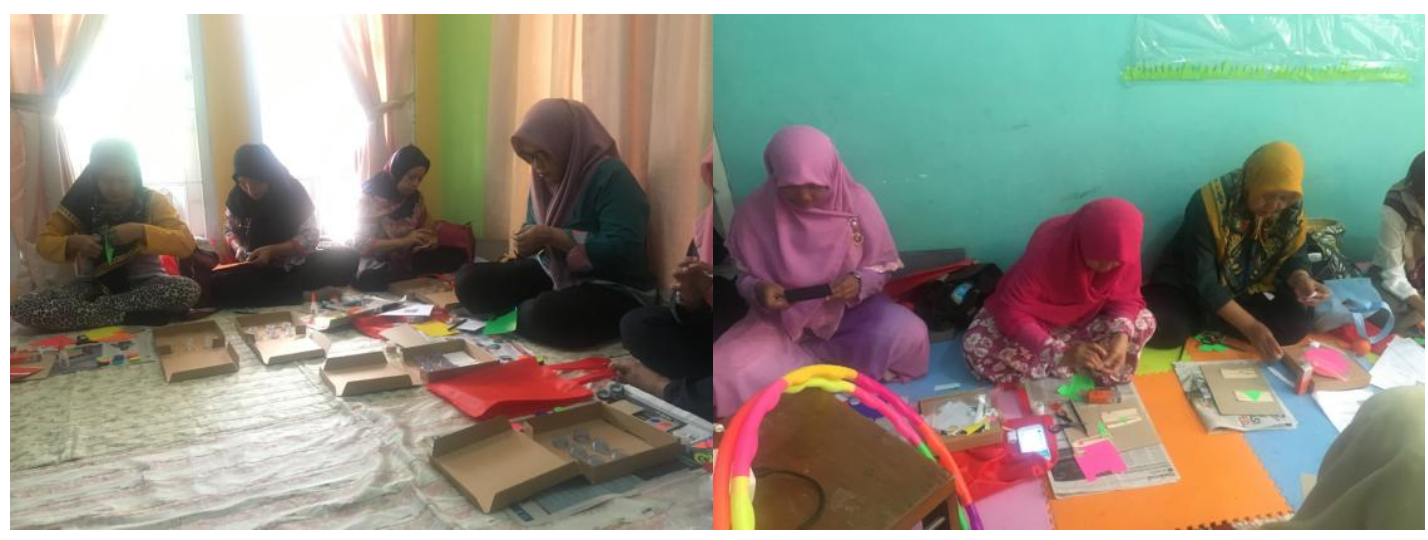

Gambar 3 Peserta sedang mengembangkan media pembelajaran

3. Pelaksanaan sesi ketiga pada pukul 11.30-12.00 WIB. Pada sesi ini peserta pelatihan diminta melakukan peer teaching menggunakan media pembelajaran yang telah dikembangkannya.

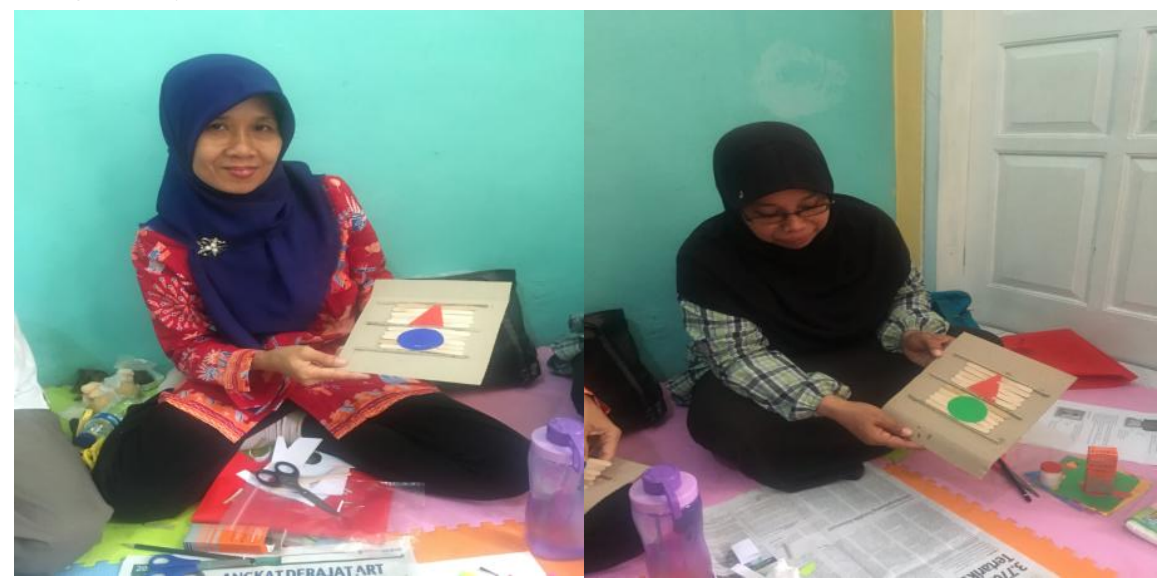

Gambar 4 Peserta sedang melakukan peer teaching menggunakan media yang telah dikembangkan

Pelaksanaan kegiatan pengabdian masyarakat tidak mengalami kendala dan mendapat sambutan yang sangat baik dari peserta yang merupakan guru PAUD di wilayah kelurahan Pengadegan. Hal ini terlihat dari semangat dan keaktifan peserta 
untuk mengikuti kegiatan pelatihan pengembangan media pembelajaran inovatif dari bahan daur ulang.

Dari kegiatan pelatihan pengembangan media pembelajaran inovatif ini tim abdimas mendapat apresiasi dari peserta, diantaranya dari hasil evaluasi menunjukkan bahwa peserta pelatihan berpendapat bahwa pelatihan ini sangat bermanfaat. Selain itu, peserta menyatakan akan menerapkan hasil pelatihan ini dalam pembelajaran di kelasnya. Peserta juga menyatakan bahwa perlu pendampingan berkelanjutan dengan mengadakan pelatihan lain yang dapat mendukung pembelajaran untuk anak usia dini dan peningkatan kompetensi guru PAUD.

\section{SIMPULAN}

Secara keseluruhan kegiatan pengabdian masyarakat yang dilakukan dapat berjalan dengan baik. Guru sebagai peserta pelatihan antusias dalam mengikuti kegiatan yang dilaksanakan oleh tim abdimas. Dengan adanya pengetahuan dan keterampilan mengenai pengembangan media pembelajaran inovatif ini, guru dapat memiliki wawasan, minat, dan kreativitas yang tinggi dalam mengembangkan media pembelajaran serta termotivasi untuk mengaplikasikan keterampilan mengembangkan dan menggunakan media pembelajaran dalam kegiatan mengajarnya, sehingga dapat mengembangkan pengetahuan dan keterampilan motorik anak usia dini.

\section{DAFTAR PUSTAKA}

Adiningsih, N. U. (2001). Pendidikan Anak Usia Dini. Jakarta: Rineka Cipta

Hariyanti, D.P.D. (2012.) Peningkatan Kinerja Guru PAUD dalam Rangka Pengembangan Karakter Peserta Didik. E-prosiding Universitas PGRI Semarang.

Marienda, W., Moch Zainuddin \& Eva N., H. (2015). Kompetensi dan Profesionalisme Guru Pendidikan Anak Usia Dini. Prosiding Kesejahteraan Sosial Penelitian \& pengabdian kepada Masyarakat Universitas Padjajaran (hlm.147-156)

Nugroho. (2014). Leadership challenges of early childhood institution. Indonesian Journal of Early Childhood Education Studies, 3(2) (2014).

Prihatin, E. (2012). Analisis kebijakan Pendidikan Anak Dini Usia (PADU). Jurnal Abmas: Media informasi pengabdian kepada masyarakat.

Ratnaningsih, I., Z., U. Prihatsanti \& A., R., Prasetyo (2015). Pelatihan bagi Kader Pendidikan Anak Usia Dini (PAUD) Kecamatan Banyumanik Semarang. Jurnal INFO, 17(2) hlm. 97-110

Suyanto, S. (2005). Dasar - dasar Pendidikan Anak Usia Dini. Yogyakarta: Hikayat. 